\title{
Adhesion and biofilm formation of Candida albicans on native and Pluronic-treated polystyrene
}

\footnotetext{
* Corresponding author:

Dr K. E. Wesenberg-Ward

Department of Chemical Engineering

Montana State University-Bozeman

Bozeman, MT 59717

USA

T 14065707201

F 14069945308

E Karemw@aol.com

1 Department of Chemical Engineering, Montana State University-Bozeman, Bozeman, MT 59717, USA

2 Department of Chemical and Fuels Engineering, University of Utah, Salt Lake City, UT 84112, USA
}

\author{
K. E. Wesenberg-Ward ${ }^{1 *}$, B. J. Tyler ${ }^{2}$ and J. T. Sears ${ }^{1}$
}

\begin{abstract}
Candida albicans forms part of the normal human flora whose growth is usually restricted by the normal flora bacteria and the host's immune system. It is an opportunistic fungal pathogen that causes infections in immunocompromised individuals, mechanical trauma victims and iatrogenic patients. Candida albicans can ingress the human host by adhering to a plastic surface (i.e. prosthetic devices, catheters, artificial organs, etc.) that is subsequently implanted, and forms a protective biofilm that provides a continuous reservoir of yeast to be hematogenously dispersed. In order for the medical profession to battle device-related infections, initial adhesion and biofilm formation of C. albicans needs to be better understood. There has been some skepticism as to whether the initial adhesion events bear any relationship to subsequent biofilm formation. Thus, to better comprehend the relationship between the initial adhesion rates and growth rate and biofilm formation, these events were studied on two different, well-defined culture surfaces, native polystyrene and Pluronic F127-conditioned polystyrene. The adhesion studies determined that Pluronic F127 adsorption dramatically reduced the adhesion of C. albicans to polystyrene. The biofilm growth studies, analyzed by confocal scanning laser microscopy, revealed that Pluronic F127 decreased the biofilm surface coverage, cluster group size, thickness and the presence of hyphal elements over the untreated polystyrene. These findings indicate that the effect of a material's surface chemistry on the initial adhesion process has a direct influence on subsequent biofilm formation.
\end{abstract}

\section{INTRODUCTION}

Approximately one in five U.S. citizens has a long-term implanted medical device. One of the most common complications associated with implanted medical devices is infectious biofilms. Most studies of infectious biofilms have been concerned with bacterial biofilms. Devicecentered infections are quite resistant to the body's immune system, antibiotics and antifungal agents (Costerton et al., 1999). Since one-quarter of the implant infections are caused by the yeast Candida albicans, the necessity for gaining insight into the initial adhesion process and ensuing biofilm development becomes apparent. Candidiasis, the infection caused by species of Candida, with $C$. albicans being the primary etiologic agent, represents an opportunistic disease. Candida albicans exists as a normal commensal of the human gastrointestinal and genitourinary tracts and mucosa. The infection stems from an overgrowth of this normal human flora. Groups susceptible to the disease include immunocompromised individuals, mechanical trauma victims and those undergoing iatrogenic procedures (Odds, 1979; Kuby, 1994).
Several possible factors are thought to contribute to the virulence of $C$. albicans. Those relevant to this study include hyphal formation, adherence properties and variable characteristics such as the dynamic cell surface. Hyphal formation is one of three different morphogenetic processes that C. albicans can undergo. The other processes include blastospore formation and pseudohyphal formation. The morphological state depends on the $\mathrm{pH}$, incubation temperature, inoculum size, and the composition of the growth medium (Odds, 1979; Kuby, 1994).

Candida albicans can invade the human host by adhering to a plastic surface (i.e. prosthesis, catheter, prosthetic valve, etc.) with subsequent formation of a protective biofilm and is then dispersed by means of the vascular system. By themselves, antifungal agents are not capable of preventing and controlling yeast bloodstream infections (Hawser \& Douglas, 1994; Zhang et al., 1997). Combating candidal infections requires a strategy that combines the use of antifungal agents along with blocking of adhesion and biofilm growth. A well-defined culture surface provides a way to study adhesion and biofilm structure. Control over the chemical features of the surface 
allows the influence of chemistry on cell behavior to be studied.

Other investigators have shown that Pluronic conditioning on a surface inhibits the adhesion of bacteria (Bridgett et al., 1992; Portoles et al., 1994) and proteins (Harper et al., 1991; Alexandridis \& Hatton, 1995; Freij-Larsson et al., 2000) to polymer surfaces. Pluronic F127 is an amphiphilic A-B-A triblock copolymer. A is poly(ethylene oxide) (PEO), the hydrophilic segment, and $\mathrm{B}$ is poly(propylene oxide) (PPO), the hydrophobic segment. Pluronic F127 consists of 98 PEO segments and 67 PPO segments. Pluronic is thought to adhere to the plastic surface via the hydrophobic portion in such a manner that the hydrophilic portion extends into the bulk fluid, imparting a hydrophilic character to the plastic surface. Pluronic F127 is a trade name given to industrial and pharmaceutical grades of Poloxamer 407. This study shows that Pluronic F127 adsorption dramatically reduces the adhesion of $C$. albicans to polystyrene (PS). The relationship between initial adhesion rates and the longterm growth rates and biofilm formation of $C$. albicans is still highly controversial. Therefore, the objectives of this work were to compare initial adhesion and subsequent biofilm formation on native polystyrene and Pluronicconditioned PS by C. albicans. The biofilm development was investigated using confocal scanning laser microscopy (CSLM).

\section{MATERIALS AND METHODS}

\section{Culture surface preparation}

The well-defined culture surfaces included native PS and Pluronic F127-conditioned PS (PLPS). The PS surface employed was either a cleaned PS coupon or a PS surface formed on a silanized glass coverslip by spin coating. The PS coupons were 0.5 in. $(1.27 \mathrm{~cm})$ diameter disks punched from a $1 / 16$ in. $(0.16 \mathrm{~cm})$ thick sheet. The coupons were cleaned prior to experimentation or manipulation. The PS coupons were cleaned by being placed in highperformance liquid chromatography grade hexane and swirled for approximately $5 \mathrm{~s}$. The coupons were then allowed to dry. After drying, the PS coupons were set in a beaker containing methanol and sonicated at $0{ }^{\circ} \mathrm{C}$ for approximately $5 \mathrm{~min}$. The PS coupons were removed from the methanol and placed in a clean Pyrex glass container.

Glass coverslips $(43 \mathrm{~mm} \times 61 \mathrm{~mm})$ were prepared for spin coating by soaking in $5 \%(\mathrm{v} / \mathrm{v})$ dimethyldichlorosilane in toluene for a minimum of $3 \mathrm{~h}$ and then rinsed with methanol to remove the excess silanizing agent, rinsed with nanopure water, and allowed to dry at ambient conditions. The silanized coverslips were then spin coated with $5 \mathrm{wt} \%$ polystyrene (average $M_{\mathrm{r}} 230000$ ) in toluene. The PS spin-coated coverslips were prepared $24 \mathrm{~h}$ prior to experimentation or manipulation.

The PS coupons were utilized in the adhesion experiments, while the spin-coated PS coverslips were utilized in the biofilm growth experiments. The spincoated PS surface was needed to accommodate a flow cell design for the biofilm growth experiments that minimized plugging and expedited analysis with CSLM.

The Pluronic F127-treated PS surfaces were generated by soaking clean PS coupons or coverslips in a $4 \%$ Pluronic F127 solution in phosphate-buffered saline (PBS) for a minimum of $3 \mathrm{~h}$. The PBS solution was $0.01 \mathrm{M}$ and had a $\mathrm{pH}$ between 7.15 and 7.25. The conditioned PS samples were either used directly or stored for no longer than 1 week.

\section{Surface composition}

X-ray photoelectron spectroscopy (XPS) was used to confirm the surface chemical composition. XPS analysis was performed with a PHI 5600 XPS system. The operating pressure in the analysis chamber was in the $10^{-9}$ torr range. A monochromatized $\mathrm{X}$-ray source ( $\mathrm{Al} \mathrm{K} \alpha$ anode, $1486.6 \mathrm{eV}$ ) was operated at $15 \mathrm{kV}$ and $300 \mathrm{~W}$. The aperture was set to 4 , corresponding to analysis of a spot $800 \mu \mathrm{m}$ in diameter. Charge neutralization was achieved using a lowenergy electron gun. All binding energies were referenced to the hydrocarbon component $(\mathrm{C}-\mathrm{C} / \mathrm{C}-\mathrm{H})$ of the $\mathrm{C} 1 \mathrm{~s}$ peak, which was set to $285.0 \mathrm{eV}$. A pass energy of $58.7 \mathrm{eV}$ was used.

\section{Cells and culture media}

Candida albicans CA1 isolates were maintained in a subzero temperature freezer. Every month a new subculture was generated using the streak plate method of isolation. Following a $48 \mathrm{~h}$ incubation period at $35^{\circ} \mathrm{C}$, a single colony was removed from the isolation plate and transferred to a slant tube containing Sabouraud dextrose agar, generated following the manufacture's instructions. The inoculated slant tubes were incubated for $48 \mathrm{~h}$ at $35^{\circ} \mathrm{C}$ and then kept at approximately $4{ }^{\circ} \mathrm{C}$. This culture of $C$. albicans was used to perform adhesion and biofilm growth experiments. Each inoculum of C. albicans for experimentation was grown in (normal) GYEP $(5 \%$ glucose, $0.3 \%$ yeast extract, $1 \%$ bacto-peptone) broth at $35^{\circ} \mathrm{C}$ and 160 revolutions/min for $24 \mathrm{~h}$. The first inoculum was removed from a slant tube and placed in $100 \mathrm{ml}$ of sterile GYEP broth. The second inoculum was obtained from the initial broth culture of which $0.25 \mathrm{ml}$ was placed in $100 \mathrm{ml}$ of sterile GYEP broth. The GYEP broth was sterilized by autoclaving for 15 to $20 \mathrm{~min}$.

The C. albicans cells used in the growth and adhesion experiments were obtained from the second inoculum following a $24 \mathrm{~h}$ incubation period (stationary phase). Two $4 \mathrm{ml}$ portions of cells were removed from the broth culture and spun for $90 \mathrm{~s}$ at ambient conditions. The cells were rinsed three times with $2 \mathrm{ml}$ of sterile, refrigerated $0.01 \mathrm{M}$ PBS. After the final rinse, $2 \mathrm{ml}$ of sterile PBS were added to each portion of cells. The cells were combined to generate a little more than $4 \mathrm{ml}$ of cells in PBS, which were pelleted and kept on ice prior to use. The concentration of cells in this solution was determined using a hemacytometer. This solution of cells was then used to generate a new solution of cells, with a concentration of approximately $10^{7}$ cells $/ \mathrm{ml}$, to be utilized in the flow cell experiments. 


\section{Adhesion and biofilm growth experiments}

The adhesion experiments were performed in a Teflon flow cell device containing the material of interest. A Pluronic F127-treated PS coupon or native PS coupon was set in the well of the Teflon flow cell. Initially, PBS was pumped through the flow cell using a peristaltic pump to establish the desired flow rate, focus the Olympus microscope, and remove air from the flow cell assembly. The yeast cells, at a concentration of approximately $1 \times 10^{7}$ cells $/ \mathrm{ml}$, were then introduced into the flow cell. A shear rate of $16 \mathrm{~s}^{-1}$ was selected, based on arterial wall shear rates that ranged from 10 to $1000 \mathrm{~s}^{-1}$. A flow rate of $1.5 \mathrm{ml} / \mathrm{min}$ was necessary to achieve the specified wall shear rate as determined by the design of the flow cell. The adhesion process was conducted at room temperature and observed for $1 \mathrm{~h}$. The progress of the experiment was monitored using an Olympus microscope (phase contrast microscopy in the reflected light mode) fitted with a $20 \times$ objective under $10 \times$ or $15 \times$ magnification and recorded through Imaging Program for Windows ${ }^{\circledR}$.

The biofilm growth experiments on the culture surface were conducted in a Kynar flow cell device that was maintained at approximately $37^{\circ} \mathrm{C}$. The sample to be studied was placed in the flow cell and then disinfected with a $5 \%$ bleach solution for $15 \mathrm{~min}$ followed by rinsing with PBS for 15-30 min, which also allowed for the creation of the required flow rate. Following a $30 \mathrm{~min}$ seeding (adhesion) period, the cells within the flow cell were fed a sterile, cell-free reduced GYEP broth $(0.05 \%$ glucose, $0.03 \%$ yeast extract, $0.1 \%$ bacto-peptone), for approximately $48 \mathrm{~h}$ to allow for the development of a biofilm. Acridine orange (AO), a cationic dye, binds to DNA and RNA and can be used in CSLM. The biofilm cultivated after the $48 \mathrm{~h}$ growth period was stained with a $0.05 \%$ AO solution in PBS for $15-30 \mathrm{~min}$, depending on the length of time needed for AO penetration of the biofilm. The excess AO was removed by pumping PBS through the flow cell until the effluent ran predominantly clear and the biofilm could now be imaged.

\section{Pluronic F127 toxicity analysis}

Toxicity tests were conducted by generating growth curves for CA1. The growth curves were produced for suspension cultures at $37^{\circ} \mathrm{C}$ in reduced GYEP broth either with or without $0.04 \%$ (v/v) Pluronic F127. Growth curves were also generated for suspension cultures at $37^{\circ} \mathrm{C}$ in normal GYEP broth with $0.0004 \%, 0.04 \%$ (v/v), or no Pluronic F127.

Owing to the difference in the effect of chemicals on planktonic cells versus their sessile counterparts, the impact of Pluronic F127 adsorbed onto the surface on cell viability was examined using propidium iodide (PI). Cells on or near the surface following the initial adhesion event $(60 \mathrm{~min})$ and extended biofilm growth $(48 \mathrm{~h})$ were stained with $25 \mu \mathrm{g} \mathrm{PI} / \mathrm{ml}$. Staining "live" cells and "dead" cells tested the reliability of PI in identifying non-viable cells of C. albicans. The "live" cells were obtained from a $35^{\circ} \mathrm{C}$ stationary phase suspension culture. The "dead" cells were obtained by autoclaving the "live" cells for 15 to $20 \mathrm{~min}$. Both groups of cells were stained with $25 \mu \mathrm{g}$ $\mathrm{PI} / \mathrm{ml}$ and loaded into a hemacytometer. The cells in one of the four corner blocks were counted and the percentage of compromised cells was established. Compromised cells fluoresced red under ultraviolet (UV) light as observed using an Olympus microscope fitted with a $20 \times$ objective (Olympus DplanApo 20 UV) under $15 \times$ magnification. In staining heat-killed cells with PI, all of the cells counted fluoresced red, whereas only $2 \%$ of CA1 cells fluoresced red. On the basis of these results, PI appeared to be a reliable measure of whether cells within the biofilm were compromised.

\section{Biofilm imaging}

CSLM was used to obtain a three-dimensional image of the $C$. albicans biofilm. The biofilm was examined using a Leica DMRXE microscope with a $63 \times$ dry objective 0.70 PL Fluotar or with a $20 \times$ dry objective Nplan having working distances of $2.0 \mathrm{~mm}$ and $2.52 \mathrm{~mm}$, respectively, dual Mitsubishi Diamond Pro 91 TXM monitors, and the Leica TCS NT imaging program. The CSLM was fitted with an argon ion laser, $488 \mathrm{~nm}$ wavelength, that was used to excite the AO. When bound to DNA, AO has excitation and emission wavelengths of $500 \mathrm{~nm}$ and $526 \mathrm{~nm}$, respectively. The excitation and emission wavelengths for $\mathrm{AO}$ bound to RNA are $460 \mathrm{~nm}$ and $650 \mathrm{~nm}$, respectively. Images were acquired at $4-5 \mu \mathrm{m} z$-intervals, with the pinhole setting at 1.00 . On average, 7-10 regions were examined during each of three experiments for the two materials. An average of 4-12 optical sections, $158.7 \mu \mathrm{m} \times$ $158.7 \mu \mathrm{m}$, were collected, depending on the thickness of the biofilm. Each optical section was averaged twice in an effort to eliminate visual noise. The last visible layer next to the surface was the last image that was obtained. That is to say, an image of the surface itself was not procured. This becomes important when we discuss the location of the thickest portion of the biofilm. Quantitative analysis of the biofilm was performed using the UTHSCSA ImageTool program (developed at the University of Texas Health Science Center at San Antonio, Texas, USA, and available over the the Internet by anonymous FTP from $<$ ddsdx.uthscsa.edu/dig/itdesc.html>) (Silyn-Roberts \& Lewis, 1997).

\section{RESULTS AND DISCUSSION}

To confirm the presence of the desired chemical species on the surfaces, the native PS and PLPS were subjected to XPS analysis. The surfaces were prepared $24 \mathrm{~h}$ prior to examination to ensure that the samples were dry, preventing out-gassing of the sample, and to minimize the possibility for contamination. Table 1 presents the carbon and oxygen surface concentrations. The surface oxygen on PS was the result of oxidation of the surface upon exposure to air. The increase in the surface oxygen content of PS upon treatment with Pluronic F127 was attributed to the presence of ether-type carbon ( $\underline{\mathrm{C}}-\mathrm{O}-\mathrm{C}$ ) evidenced by a C1s component near $286.5 \mathrm{eV}$. 
Table 1: XPS atomic concentrations

\begin{tabular}{lll}
\hline & \multicolumn{2}{c}{ Concentration (\%) } \\
\cline { 2 - 3 } Element & Pristine polystyrene & $\begin{array}{l}\text { Pluronic F127-conditioned } \\
\text { polystyrene }\end{array}$ \\
\hline C1s & 98.40 & 89.60 \\
O1s & 1.60 & 10.40 \\
\hline
\end{tabular}

The results of the adhesion experiments of $C$. albicans to PS and PLPS are summarized in Fig. 1, which shows the number of cells adhering to an area of $1 \mathrm{~mm}^{2}$ after exposure for $1 \mathrm{~h}$ to a cell concentration of approximately $1 \times 10^{7}$ cells $/ \mathrm{ml}$ at a rate of $1.5 \mathrm{ml} / \mathrm{min}$. The number of cells that adhered to PLPS $\left(116 \pm 31\right.$ cells $\left./ \mathrm{mm}^{2}\right)$ was

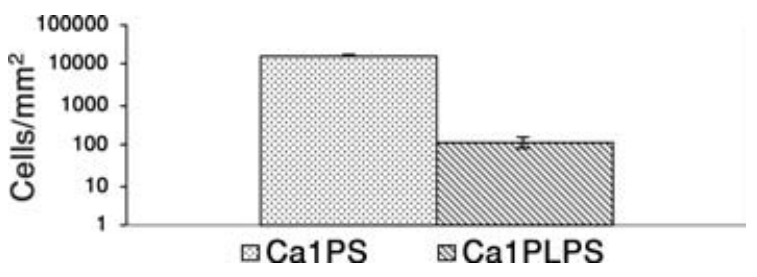

Fig. 1: Adhesion of C. albicans (Ca) to treated (PLPS) and untreated (PS) polystyrene after $60 \mathrm{~min}$ of exposure to a cell concentration of approximately $1 \times 10^{7}$ cells $/ \mathrm{ml}$ at a rate of $1.5 \mathrm{ml} / \mathrm{min}$. Values are expressed as mean number of cells per unit area. The error bar represents the standard deviation.

significantly less than that which adhered to PS (16241 \pm 540 cells $/ \mathrm{mm}^{2}$ ).

The results from the $1 \mathrm{~h}$ adhesion experiments prompted the question of whether the influence of

\section{(a)}

First cell layer
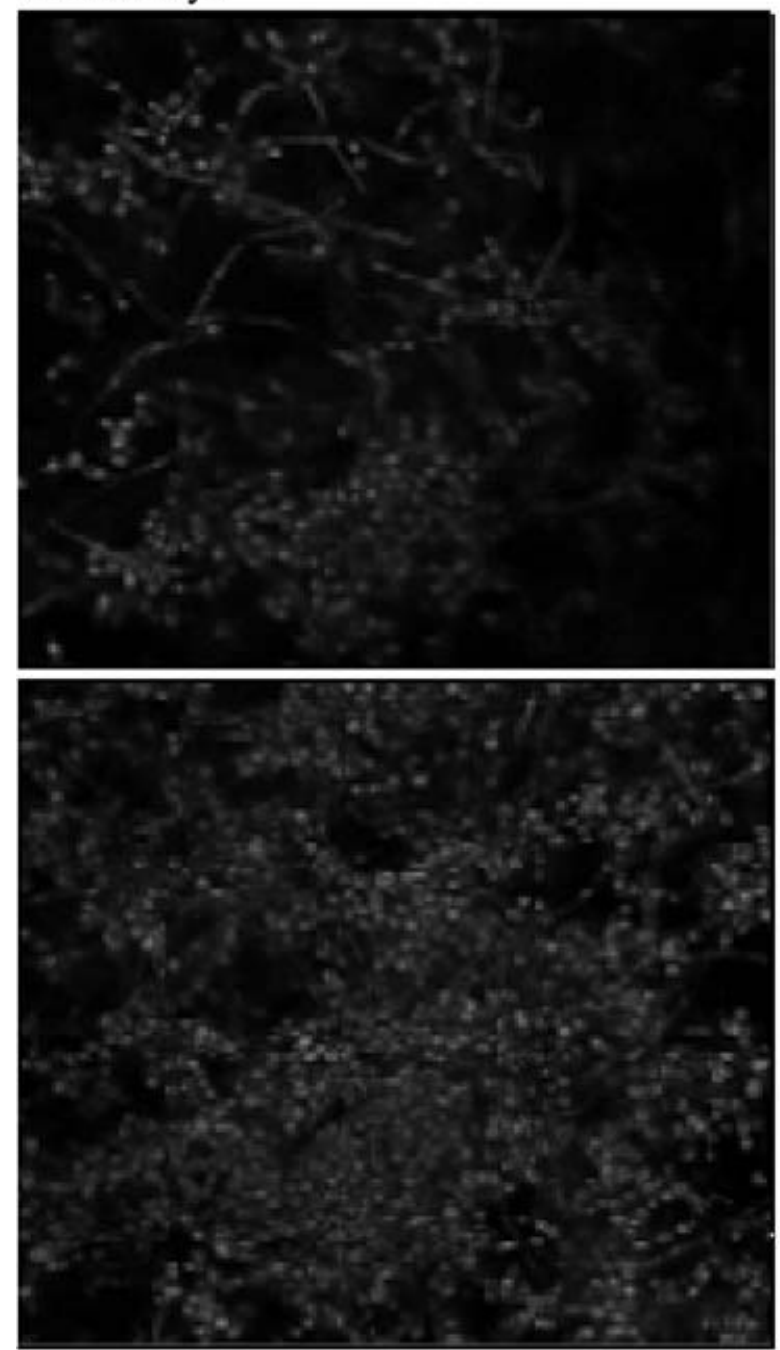

$\sim 10 \mu \mathrm{m}$
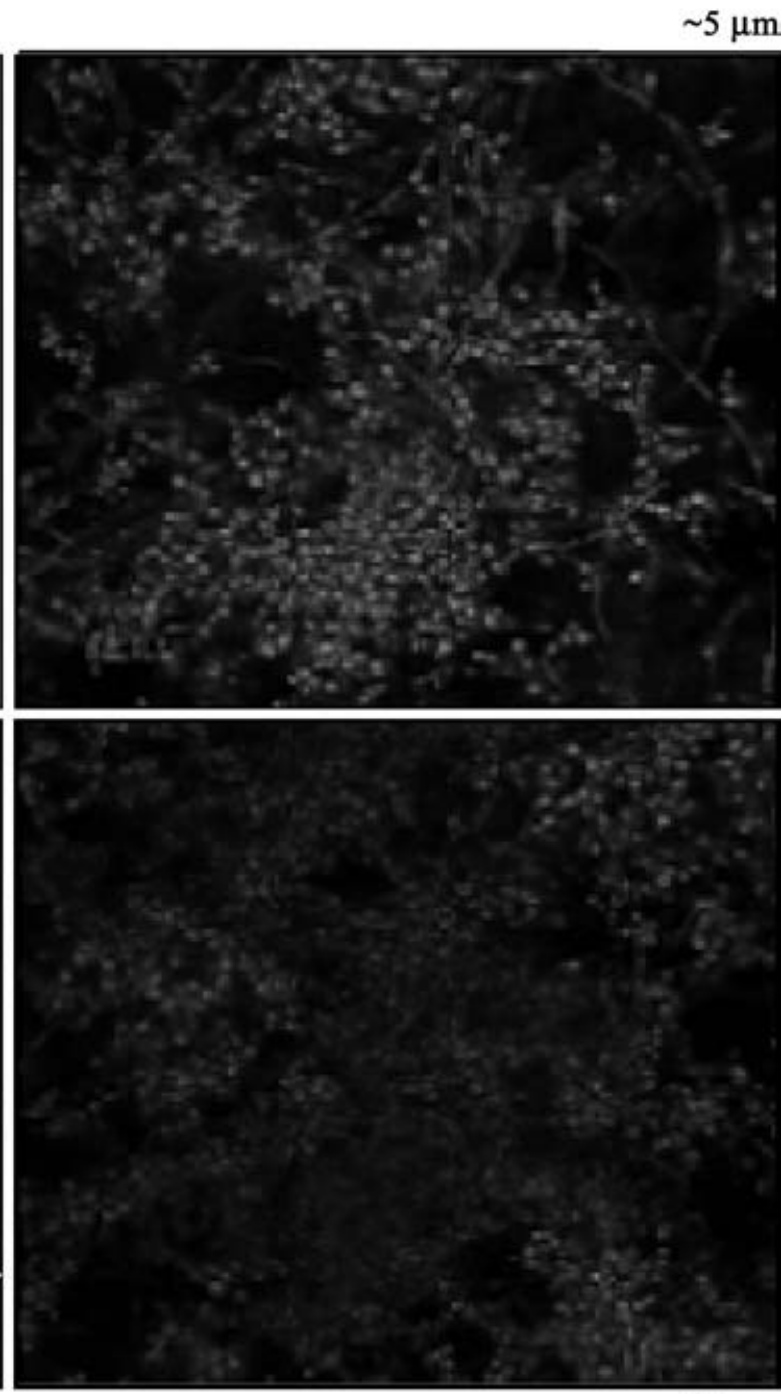

$\sim 15 \mu \mathrm{m}$

Fig. 2: (a) Biofilm formation on pristine polystyrene at $48 \mathrm{~h}$ : the first cell layer was at the surface and the consecutive layers given in approximately $5 \mu \mathrm{m}$ increments. (b) Biofilm formation on Pluronic F127-conditioned polystyrene at $48 \mathrm{~h}$ : the first cell layer was at the surface and consecutive layers given in approximately $4 \mu \mathrm{m}$ increments. 
(b)
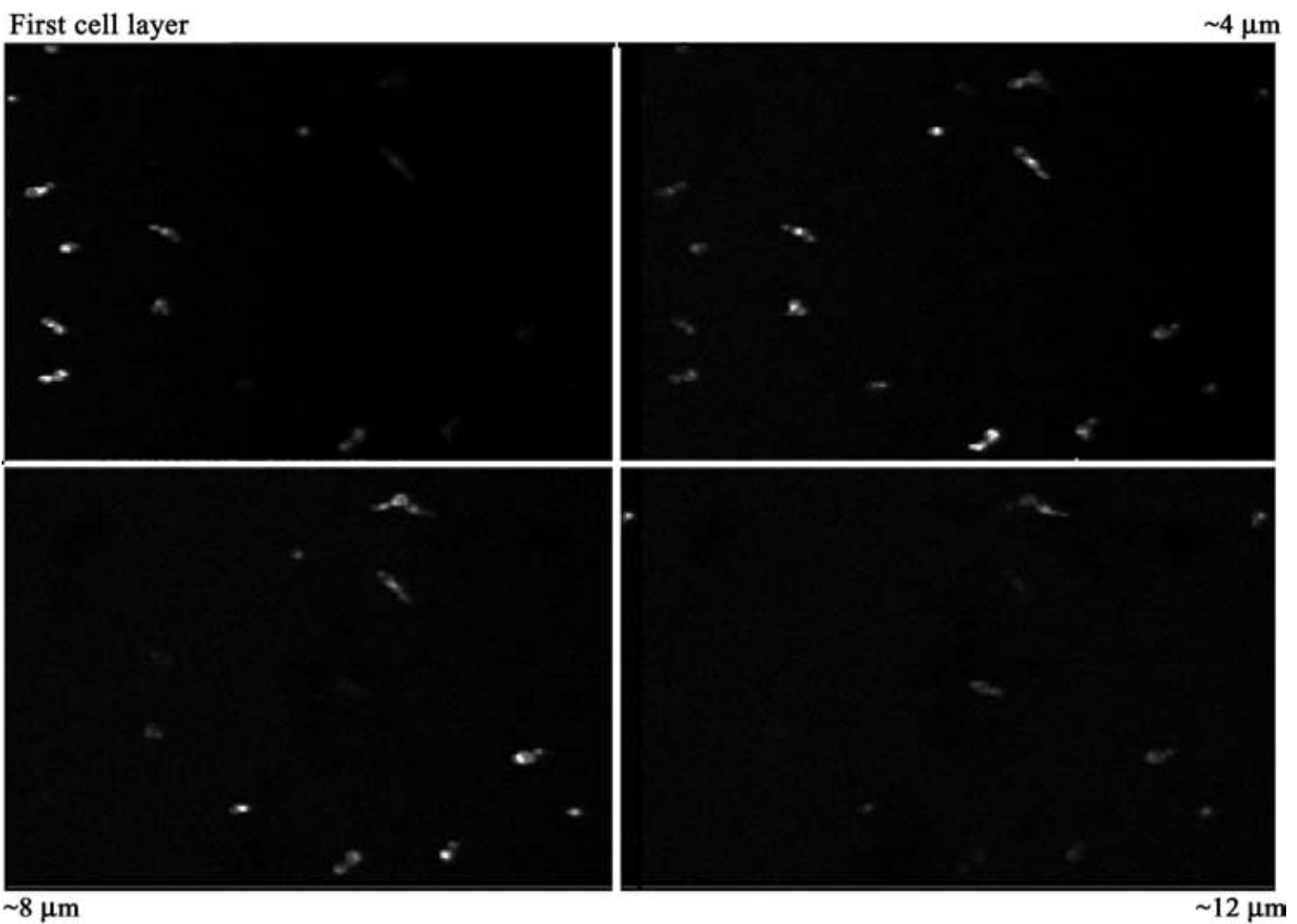

$\sim 8 \mu \mathrm{m}$

$\sim 12 \mu \mathrm{m}$

Fig. 2: Continued.

Pluronic F127 on initial cell adhesion persists during the formation of the biofilm. The biofilms that formed on the pristine PS and on the Pluronic F127-treated PS were strikingly different. Fig. 2 displays CSLM images for a C. albicans biofilm formed on PS and PLPS following $48 \mathrm{~h}$ of growth at approximately $37^{\circ} \mathrm{C}$. The CSLM images show four layers of a biofilm, beginning at the first layer of visible cells and extending towards the bulk fluid. The first layer of visible cells was determined by scanning through the biofilm until no cells were observed and then scanning back up to the first layer of visible cells.

If the attached cells are termed a biofilm, Fig. 3 shows the percentage surface coverage for biofilm $(48 \mathrm{~h})$ formation on PS and PLPS as a function of distance above the first cell layer. Height zero represents the first visible layer of cells on the surface. As yeast cells have an average diameter of $5 \mu \mathrm{m}$, this seems to indicate that the greatest surface coverage occurs at the second cell layer beyond the substratum; however, it may also be that the biofilm actually begins on average near the $5 \mu \mathrm{m}$ point and the reason some cells are observed below this point may be due to an artifact such as the surface not being completely level. Also, as the biofilm was scanned, some cells appeared clearly at one level and faintly at levels above and below, and the distorted appearance of the cells may be a consequence of passing the laser through air-solid-liquid interfaces.
These factors may then influence the initial layer image and the biofilm thickness obtained from the confocal imaging. The heterogeneous nature of the biofilm on PS resulted in a surface coverage ranging from approximately $10 \%$ to approximately $60 \%$ at its apex, and the total thickness ranged from 20 to $60 \mu \mathrm{m}$. This thickness is similar to that expected from a mature bacterial biofilm $(50-100 \mu \mathrm{m})$. The percentage surface coverage reached a peak at a height of approximately $5 \mu \mathrm{m}$ from the surface layer of cells and tapered off into the bulk fluid. The average maximum surface coverage for the three experiments was $21 \%$. On PLPS, a very spotty "biofilm" was formed and less than $1 \%$ of the surface was covered. At the maximum surface coverage of $0.5 \%$ on PLPS and $21 \%$ on PS, there is a very observable difference.

Does this indicate that PLPS will stop C. albicans biofilm formation in the long term? The number of cells on PLPS changed very little over the $48 \mathrm{~h}$ growth period whereas the biofilms grown on native polystyrene increased dramatically over what was observed during the initial attachment stage. It is known that bacterial biofilms can slowly colonize a surface even though initial colonization is reduced by some treatments. However, this is due to the degradation of the surface and interactions between cell clusters. Pluronic F127-treated surfaces are inherently resistant, since it is the oxygen/hydrophilic 

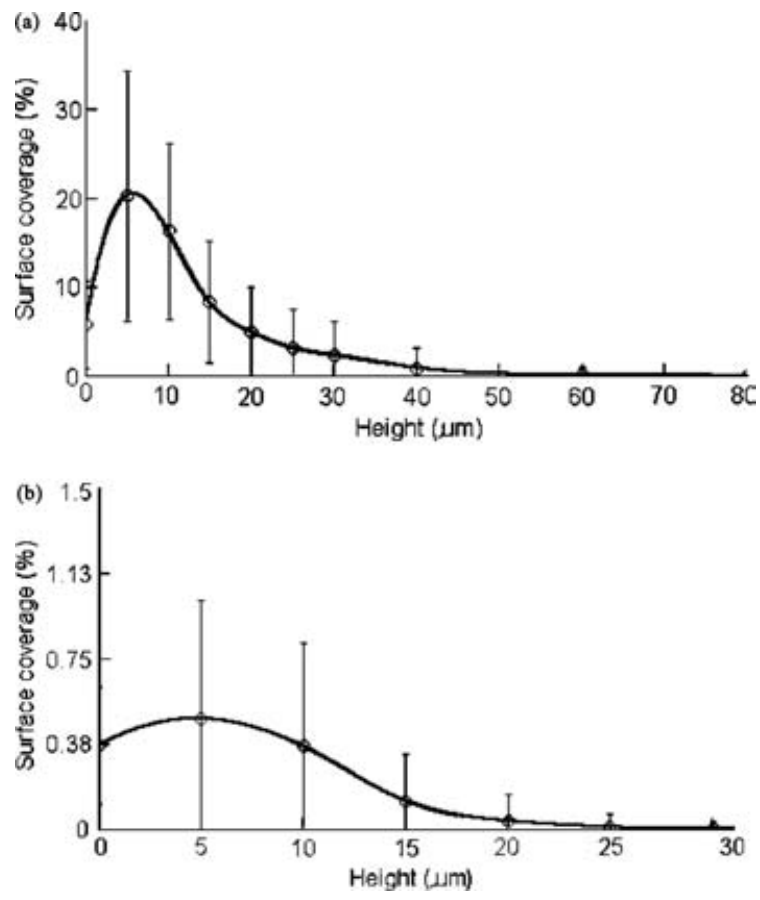

Fig. 3: Mean percentage surface coverage versus distance from the first cell layer for PS and PLPS. (a) Three experiments with an average of 10 regions of the biofilm formed on pristine polystyrene per experiment. (b) Four experiments with an average of seven regions of the biofilm formed on Pluronic F127-conditioned polystyrene per experiment. The bars on the graph represent the standard deviation of the coverage due to heterogeneity of the biofilm.

surface that seems to be the resistant phase, and the attached yeast clusters are far apart and unlikely to interact and foul. Preliminary results on the adhesion of C. albicans to oxygen-plasma-treated PS revealed limited attachment (768-448 cells $\left./ \mathrm{mm}^{2}\right)$. As long as the oxygen/hydrophilic surface remains and is not removed from the surface, it is very likely that the surface will not foul. The PEO segments should ideally be covalently grafted to the surface.

Candida albicans tends to form cell clusters. The various cluster groups within each layer of the biofilm were therefore classified into different cluster sizes. Representative images and the cluster sizes that were considered are shown in Fig. 4. The smallest cluster group consisted of single cells and budding cells. The bar graphs displayed in Fig. 5a,b indicate the cluster group fraction of the total cluster area in each layer of the biofilm. Both graphs reveal in general that the largest of the total cluster groups (gray) represent the greatest fraction of the total cluster area in regions close to the surface, and the smallest cluster groups (diagonal hatching) occupy the greatest fraction of the total cluster area in regions distant from the surface. The appearance of large cluster groups on PLPS has decreased dramatically in comparison to that associated with the biofilms formed on untreated PS.

The recalcitrance of bacterial biofilms is thought to be a multicellular endeavor. Degradation of hydrogen peroxide by catalase produced by bacterial cells requires a concerted effort by a group of cells. Similarly, the activity of some

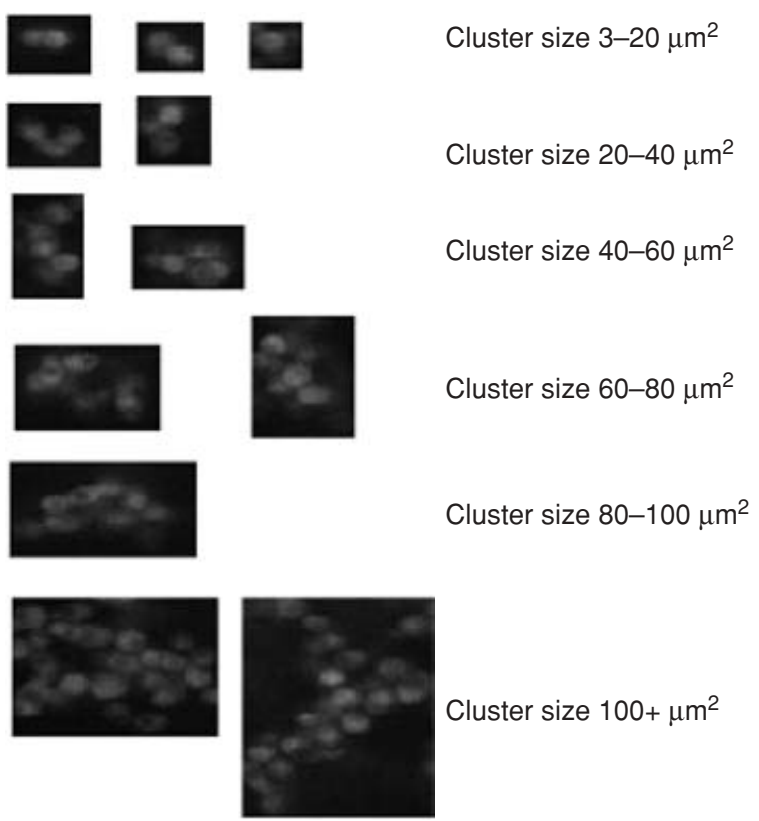

Fig. 4: Examples of each cluster size used in quantifying the biofilm that formed on treated and untreated polystyrene.

antibiotics requires oxygen. The cells on the perimeter of the biofilm consume the oxygen and thereby protect their deeper neighbors (Netting, 2001; Stewart, 2001). Biofilm bacteria generate signal transduction proteins that gather information from the environment and relay it to chromosomal elements. This form of communication allows for a group virulence response. This type of gene regulation, termed "quorum sensing and response", requires a sufficient population size (Davies et al., 1998; Reid, 1999). Biofilms also act as a diffusion barrier, with the maximum diffusion distance increasing as the cluster size increases (El-Azizi \& Khardori, 1999; Jenkinson \& LappinScott, 2001). Thus smaller clusters and/or the absence of biofilm cell clusters would seem to necessarily restrict the multicellular response thought to support biofilms.

The formation of hyphal elements within the biofilm was frequently observed on native PS. However, upon treatment with Pluronic F127, the expression of hyphal elements was scarce. The CSLM images displayed in Fig. 6 reveal the typical presence of hyphal elements within a biofilm formed on native PS (Fig. 6a) and the rare appearance of hyphal elements within a biofilm formed on PLPS (Fig. 6b).

Hyphal formation, along with being a major virulence factor, has been shown to be necessary for formation of normal biofilms by C. albicans. Ramage et al. (2002) demonstrated the importance of the EFG1 gene in the development of C. albicans filamentous form and biofilms that display the typical three-dimensional architecture. Similarly, Baillie \& Douglas (1999) showed that a C. albicans mutant strain (1001-92') unable to produce hyphae also formed atypical biofilms. The EFG1 mutant strains formed a thinly distributed layer of elongated cells. The hyphal-mutant strain utilized by Baillie \& 
(a)

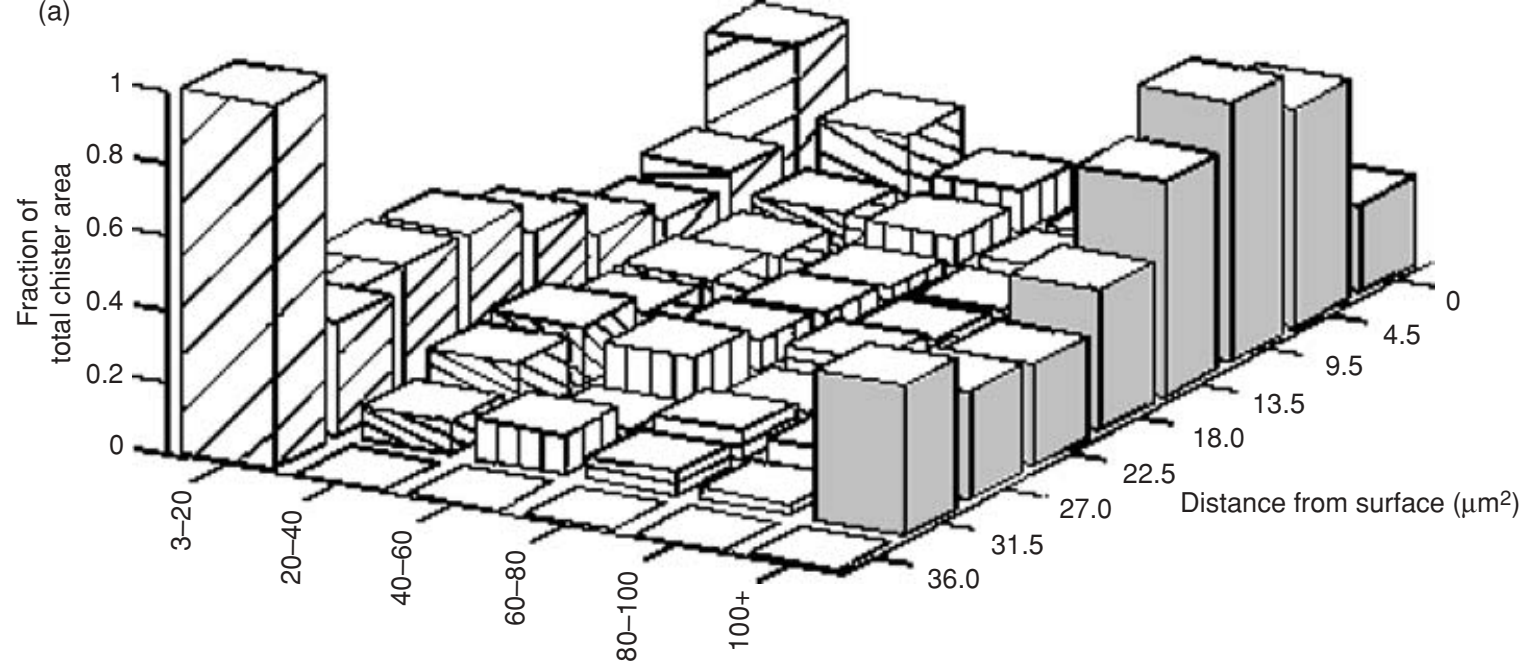

Chister size $\left(\mu \mathrm{m}^{2}\right)$

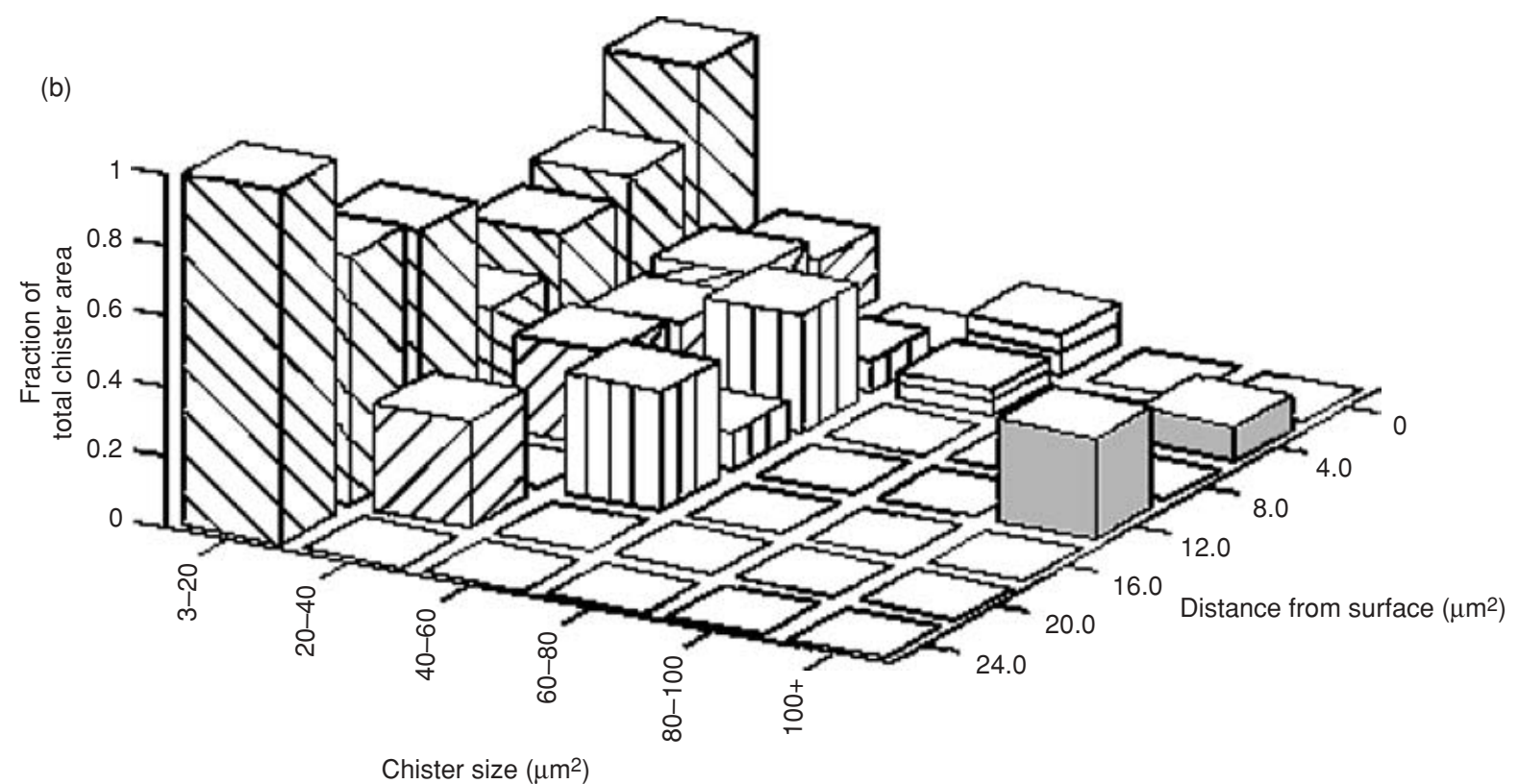

Fig. 5: Cluster group fraction of the total cluster area in each layer of the biofilm formed on (a) pristine polystyrene averaged for eight regions of the biofilm on each of three experiments and (b) Pluronic F127-conditioned polystyrene averaged for seven regions of the biofilm.

Douglas developed a monolayer of compact yeast cells. The biofilms generated by the mutant strains in both studies were found to be resistant to the antifungal agent amphotericin B. The EFG1 mutant biofilms were also resistant to the antifungal agent fluconazole. However, the EFG1 mutant strain had sessile minimum inhibitory concentrations at $80 \%$ inhibition of $1 \mu \mathrm{g} / \mathrm{ml}$ by comparison with $8 \mu \mathrm{g} / \mathrm{ml}$ for strain CAF-2, which served as the control. The response of the cells that attached to the Pluronic F127-treated surface to antifungal agents was not measured.

In an attempt to determine whether Pluronic F127 is toxic to C. albicans, the surfactant $(0.04 \%(\mathrm{v} / \mathrm{v}))$ was added to the growth medium of a suspension culture as described in Materials and Methods, above. The growth profile for $C$. albicans grown in medium containing Pluronic F127 was compared with those generated for cells grown in the absence of the surfactant. The results from analysis of variance indicated that Pluronic F127 (0.04\% $(\mathrm{v} / \mathrm{v}))$ significantly decreased the log concentration of cells $(P<0.0001)$ and decreased the $24 \mathrm{~h}$ plateau level by approximately one-third. However, because of the differences in chemical sensitivity observed between sessile cells and their planktonic counterparts (Hawser \& Douglas, 1995; Chandra et al., 2001), we investigated the potential effect of Pluronic F127 on cells within a biofilm, formed on a surface modified by adsorption of Pluronic F127. 
(a)
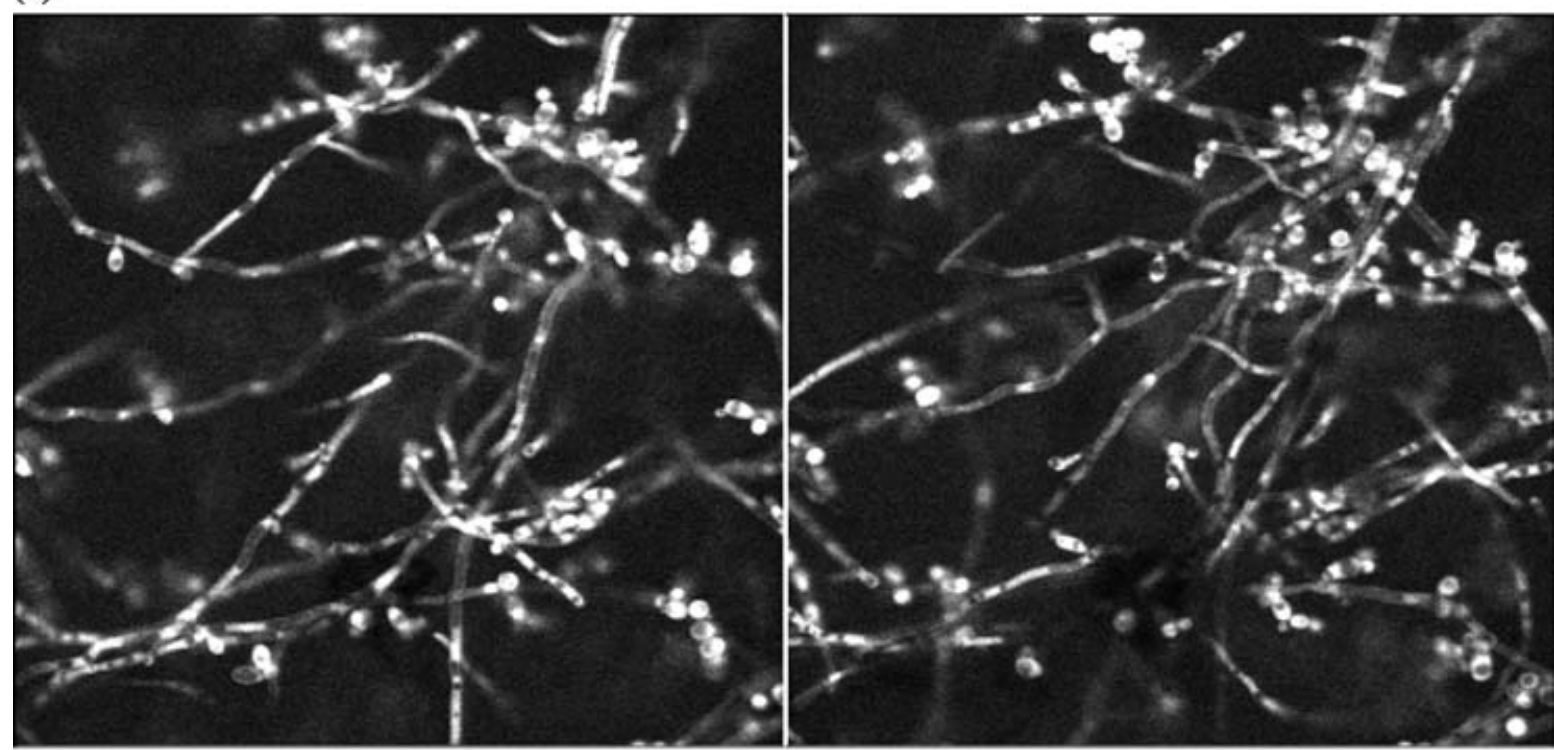

(b)
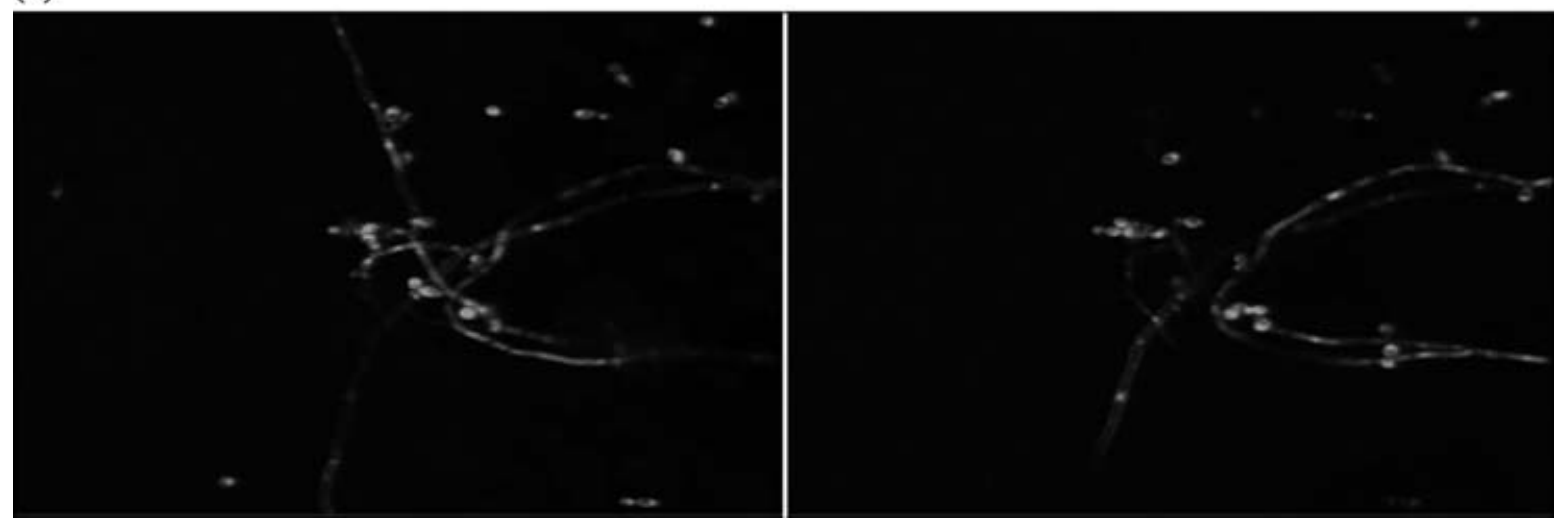

Fig. 6: Hyphal formation on pristine polystyrene (a) and on Pluronic F127-conditioned polystyrene (b) after $48 \mathrm{~h}$ of biofilm growth.

Observation of PI-stained biofilms using CSLM revealed that CA1 biofilms formed on PS had regions that fluoresced red (i.e. were stained with PI and therefore presumably compromised) in most of the areas of the biofilm examined. However, the regions stained by PI were small in comparison with the total area of the biofilm. In contrast, regions of CA1 biofilms generated on PLPS that were stained by PI constituted a greater portion of the total cellular area. However, less than half of the regions examined were stained. Those cellular components that fluoresced red were hyphal elements, but not all hyphal elements observed were stained. One should also consider the findings of others that Pluronic alters the permeability of cells (Laouar et al., 1996). Therefore the cells that are stained may be stained as a result of increased cell permeability and not as a consequence of cell death. On the basis of these results, it is not evident that Pluronic F127 is toxic to the yeast cells on the surface. The antiadhesive quality of Pluronic F127 towards C. albicans is probably due to steric stabilization of the surface, as has been indicated for bacteria and proteins, rather than a product of toxicity (Bridgett et al., 1992; Alexandridis \& Hatton, 1995; Freij-Larsson et al., 2000).

To summarize, images were taken during development of a $48 \mathrm{~h}$ biofilm, and the thickness of the biofilm on an untreated substratum was $40-50 \mu \mathrm{m}$, a reasonable thickness for a mature biofilm. This work established that Pluronic F127 addition to PS reduced the adhesion of C. albicans to PS by more than two orders of magnitude. Pluronic F127 treatment similarly diminished the mean surface coverage from $21 \%$ to $0.5 \%$ at approximately $5 \mu \mathrm{m}$ (the maximum visible cell layer on the surface). Pluronic F127 treatment reduced hyphal formation, an important virulence factor and also curtailed the formation of large clusters of cells, perhaps by minimizing the adhesion. It was also shown that the smallest cluster groups represent the greatest fraction of the total area of clusters throughout the biofilm. These results can be used, with some caution, to indicate that Pluronic F127 treatment of a surface can inhibit the formation of a fungal biofilm of C. albicans. 
Long-term studies are needed to establish whether the effect is important on implant devices. On the basis of these studies, it appears that the effect of surface chemistry on the initial adhesion events persists during the development of the biofilm - limited adhesion results in limited biofilm growth.

\section{ACKNOWLEDGEMENTS}

This work was supported by: the Center for Biofilm Engineering, Montana State University-Bozeman; the ICAL, Montana State University-Bozeman; NIH Grant R01 DE 013231-01; and UTHSCSA ImageTool and NIH Image J.

\section{REFERENCES}

Alexandridis, P. \& Hatton, T. A. (1995) Poly(ethylene oxide)-poly(propylene oxide)-poly(ethylene oxide) block copolymer surfactants in aqueous solutions and at interfaces: thermodynamics, structure, dynamics, and modeling. Colloids and Surfaces A: Physiochemical and Engineering Aspects 96, $1-46$

Baillie, G. S. \& Douglas, L. J. (1999) Role of dimorphism in the development of Candida albicans biofilms. Journal of Medical Microbiology 48, 671-679

Bridgett, M. J., Davies, M. C. \& Denyer, S. P. (1992) Control of staphylococcal adhesion to polystyrene surfaces by polymer surface modification with surfactants. Biomaterials 13, 411-416

Chandra, J., Kuhn, D. M., Mukherjee, P. K., Hoyer, L. L., McCormick, T. \& Ghannoum, M. A. (2001) Biofilm formation by the fungal pathogen Candida albicans: development, architecture, and drug resistance. Journal of Bacteriology 183, 5385-5394

Costerton, J. W., Stewart, P. S. \& Greenberg, E. P. (1999) Bacterial biofilms: a common cause of persistent infections. Science 284, 1318-1322

Davies, D. G., Parsek, M. R., Pearson, J. P., Iglewski, B. H., Costerton, J. W. \& Greenberg, E. P. (1998) The involvement of cell-to-cell signals in the development of a bacterial biofilm. Science 280, 295-298

El-Azizi, M. \& Khardori, N. (1999) Factors influencing adherence of Candida spp. to host tissues and plastic surfaces. Indian Journal of Experimental Biology 37, 941-951
Freij-Larsson, C., Jannasch P. \& Wesslén, B. (2000) Polyurethane surfaces modified by amphiphilic polymers: effects on protein adsorption. Biomaterials 21, 307-315

Harper, G. R., Davies, M. C., Davis, S. S., Tadros, T. F., Taylor, D. C., Irving, M. P. \& Waters, J. A. (1991) Steric stabilization of microspheres with grafted polyethylene oxide reduces phagocytosis by rat Kupffer cells in vitro. Biomaterials 12, 695-700

Hawser, S. P. \& Douglas, L. J. (1994) Biofilm formation of Candida species on the surface of catheter materials in vitro. Infection and Immunity 62, 915-921

Hawser, S. P. \& Douglas, L. J. (1995) Resistance of Candida albicans biofilms to antifungal agents in vitro. Antimicrobial Agents and Chemotherapy 39, 2128-2131

Jenkinson, H. F. \& Lappin-Scott, H. M. (2001) Biofilms adhere to stay. Trends in Microbiology 9, 9-10

Kuby, J. (1994) Immunodeficiency diseases. In Immunology, pp. 509-522. New York:W. H. Freeman and Company

Laouar, L., Lowe, K. C. \& Mulligan, B. J. (1996) Yeast responses to nonionic surfactants. Enzyme and Microbiology Technology 18, 433-438

Netting, J. (2001) Sticky situations. Science News Online 160, 2

Odds, F. C. (1979) Morphogenesis in Candida, with special reference to Candida albicans (Chapter 4); Laboratory identification of Candida (Chapter 5); Ecology and epidemiology of Candida (Chapter 6); Factors that predispose the host to candidosis (Chapter 7). In Candida and Candidosis, pp. 29-92. Baltimore, MD: University Park Press

Portoles M., Refojo, M. F. \& Leong, F. (1994) Poloxamer 407 as a bacterial adhesive for hydrogel contact lenses. Journal of Biomedical Materials Research 28, 303-309

Ramage, G., VandeWalle, K., Lopez-Ribot, J. L. \& Wickes, B. L. (2002) The filamentation pathway controlled by the Efg1 regulator protein is required for normal biofilm formation and development in Candida albicans. FEMS Microbiology Letters 214, 95-100

Reid, G.(1999) Biofilms in infectious disease and on medical devices. International Journal of Antimicrobial Agents 11, 223-226

Silyn-Roberts, G. \& Lewis G. (1997) A technique in confocal laser microscopy for establishing biofilm coverage and thickness. Water Science and Technology 36(10), 117-124

Stewart, P. S. (2001) Multicellular resistance: Biofilms. Trends in Microbiology 9, 204

Zhang, X., Whitbourne, R. \& Richmond, R. D. (1997) Antiinfective coatings for indwelling medical devices. Medical Plastics and Biomaterials Magazine 11, 16-25 